\title{
Hormonioterapia no tratamento de câncer de mama em pacientes do sexo feminino: uma revisão integrativa
}

\author{
Hormone therapy in the treatment of breast cancer in female patients: an integrative review \\ Terapia hormonal en el tratamiento del cáncer de mama en pacientes femeninas: una revisión \\ integrativa
}

Recebido: 23/02/2021 | Revisado: 02/03/2021 | Aceito: 06/03/2021 | Publicado: 15/03/2021

\author{
Jakeline Cristina Pinheiro de Paula \\ ORCID: https://orcid.org/0000-0001-5892-532X \\ Universidade Federal de Santa Maria, Brasil \\ E-mail: jakeliiine@hotmail.com \\ Verginia Margareth Possatti Rocha \\ ORCID: https://orcid.org/0000-0002-8062-095X \\ Universidade Federal de Santa Maria, Brasil \\ E-mail: verroch@hotmail.com \\ Valéria Maria Limberger Bayer \\ ORCID: https://orcid.org/0000-0002-6731-4835 \\ Universidade Federal de Santa Maria, Brasil \\ E-mail: valeriamlbayer@gmail.com \\ Elidiane Emanueli Ficanha \\ ORCID: https://orcid.org/0000-0003-3652-2073 \\ Universidade Federal de Santa Maria, Brasil \\ E-mail: lidificanha@gmail.com \\ Edcarlos Vasconcelos da Silva \\ ORCID: https://orcid.org/0000-0002-8989-8843 \\ Universidade Federal do Amapá, Brasil \\ E-mail: edcarlos.vasconcellos@unifap.br
}

\begin{abstract}
Resumo
Objetivo: Discutir o uso da hormonioterapia e os efeitos de sua administração no tratamento do câncer de mama em pacientes do sexo feminino. Método: Revisão integrativa, realizada em julho de 2020, nas bases de dados Scopus, Web of Science e Biblioteca Virtual em Saúde, utilizando a estratégia de busca: "neoplasia da mama" [AND] "inibidores da aromatase"; "neoplasia da mama" [AND] "fulvestranto"; "neoplasia da mama" [AND] "tamoxifeno". Resultados: Foram selecionados 23 artigos, agrupados conforme a terapia utilizada. O fulvestranto (30,43\% dos artigos), obteve eficácia na pós-menopausa e em cuidados paliativos; os inibidores da aromatase (56,52\% dos artigos), obteve eficácia em associação com outro medicamento e isoladamente no câncer de mama primário e metastático; já o tamoxifeno (47,82\% dos artigos), demonstrou resultados positivos como adjuvante. Quanto aos efeitos colaterais, os três medicamentos apresentaram complicações. Ressalta-se também que o perfil das mulheres variou em idade (18 até 82 anos) e aspectos fisiológicos (pré e pós menopausa). Considerações finais: A hormonioterapia tem um papel relevante no tratamento de mulheres com câncer de mama. Entretanto, é necessário considerar as características individuais das pacientes, uma vez que efeitos adversos podem ser evitados quando o hormônio é bem administrado, alterando significativamente a qualidade de vida das pacientes.
\end{abstract}

Palavras-chave: Neoplasias da mama; Hormônios; Tamoxifeno; Inibidores da aromatase; Fulvestranto.

\begin{abstract}
Objective: Discuss the use of hormone therapy and the effects of its administration in the treatment of breast cancer in female patients. Method: Integrative review, carried out in July 2020, in the Scopus, Web of Science and Virtual Health Library databases, using the search strategy: "breast cancer" [AND] "aromatase inhibitors"; "breast cancer" [AND] "fulvestranto"; "breast cancer" [AND] "tamoxifen". Results: 23 articles were selected, grouped according to the therapy used. Fulvestranto (30.43\% of the articles), was effective in postmenopausal and palliative care; aromatase inhibitors (56.52\% of the articles), obtained efficacy in association with another medication and alone in primary and metastatic breast cancer; tamoxifen (47.82\% of the articles), demonstrated positive results as an adjuvant. As for side effects, the three drugs had complications. It should also be noted that the profile of women varied in age (18 to 82 years) and physiological aspects (pre and post menopause) Final considerations: Hormone therapy plays an important role in the treatment of women with breast cancer. However, it is necessary to consider the individual characteristics
\end{abstract}


of the patients, since adverse effects can be avoided when the hormone is well administered, significantly altering the patients' quality of life.

Keywords: Breast neoplasms; Hormones; Tamoxifen; Aromatase inhibitors; Fulvestrant.

\begin{abstract}
Resumen
Objetivo: Discutir el uso de la terapia hormonal y los efectos de su administración en el tratamiento del cáncer de mama en pacientes del sexo femenino. Método: Revisión integrativa, realizada en julio de 2020, en las bases de datos Scopus, Web of Science y Biblioteca Virtual en Salud, utilizando la estrategia de búsqueda: "cáncer de mama" [Y] "inhibidores de la aromatasa"; "cáncer de mama" [Y] "fulvestranto"; "cáncer de mama" [Y] "tamoxifeno". Resultados: se seleccionaron 23 artículos, agrupados según la terapia utilizada. Fulvestranto (30,43\% de los artículos), fue eficaz en cuidados posmenopáusicos y paliativos; los inhibidores de la aromatasa (56,52\% de los artículos), obtuvieron eficacia en asociación con otro medicamento y solos en el cáncer de mama primario y metastásico; tamoxifeno (47,82\% de los artículos), demostró resultados positivos como coadyuvante. En cuanto a los efectos secundarios, los tres fármacos tuvieron complicaciones. Cabe destacar también que el perfil de la mujer varió en edad (18 a 82 años) y aspectos fisiológicos (pre y post menopausia). Consideraciones finales: La terapia hormonal juega un papel importante en el tratamiento de mujeres con cáncer de mama. Sin embargo, es necesario considerar las características individuales de los pacientes, ya que se pueden evitar efectos adversos cuando la hormona se administra bien, alterando significativamente la calidad de vida de los pacientes.
\end{abstract}

Palabras clave: Neoplasias de la mama; Hormonas; Tamoxifeno; Inhibidores de la aromatasa; Fulvestrant.

\title{
1. Introdução
}

O câncer de mama é o tipo mais incidente de câncer no mundo, entre o sexo feminino (Cantinelli, Camach, Smaletz, Gonsale \& Braguittoni, 2006; Globocan, 2018). Devido às altas taxas de mortalidade e morbidade, o câncer de mama é um problema de saúde pública mundial, tanto em países desenvolvidos como em países subdesenvolvidos ou em desenvolvimento.

No Brasil, o câncer de mama é principal causa de óbito entre as mulheres, com um total de 17.572 óbitos. O Instituto Nacional do Câncer (INCA) estima que no Brasil, em 2020, ocorrerá cerca de 66.280 novos casos deste tipo de câncer, sendo que a estimativa da incidência no estado do Rio Grande do Sul também é elevada, com uma taxa ajustada de 42,95/100 mil mulheres, para 2020 (INCA, 2019, 2020b).

No organismo humano é possível encontrar aproximadamente 100 desordens celulares podendo acarretar o desenvolvimento de tumores malignos, entre eles, o câncer de mama, definido pelo crescimento desordenado e abrupto de células anormais nos tecidos mamários5. O câncer de mama é uma doença multifatorial e, fatores genéticos, biológicos e ambientais contribuem para a sua ocorrência4. Acomete especialmente as mulheres na faixa etária de 40 a 59 anos e torna-se mais raro em homens (Brito, Sampaio, Castro \& Oliveira, 2004; Haddad, 2010; INCA, 2020b).

Após a confirmação do diagnóstico do câncer de mama, é realizado o estadiamento da doença. O sistema de estadiamento mais utilizado é o aceito pela União Internacional Contra o Câncer (UICC), titulado Sistema TNM (tumor, comprometimento nodal e metástases) de Classificação dos Tumores Malignos. Esse sistema baseia-se na ampliação anatômica da doença, considerando as propriedades do tumor primário, as propriedades dos linfonodos das cadeias de drenagem linfática do órgão em que o tumor se encontra e a existência ou ausência de metástase a distância (Brasil, 2019a).

Com frequência, o câncer de mama é localizado no quadrante superior externo. As lesões são indolores, fixas e com margens irregulares, sendo complementares às alterações da pele quando está em fase avançada (Smeltzer, Bare, Brunner \& Suddarth, 2006). As metástases linfonodais são relativamente frequentes no câncer de mama e o estadiamento adequado do câncer é importante para otimizar o prognóstico da doença e guiar as terapias a serem adotados (Jager et al., 2010; Silva \& Gonçalves, 2017).

Nas últimas décadas o tratamento do câncer de mama tem experimentado muitos avanços, conhecimento sobre a doença e suas formas de apresentação e as variadas terapêuticas. O tipo de tratamento está sujeito ao estádio que se encontra estadiamento - e do tipo do tumor, pode ser cirurgia, radioterapia, quimioterapia, terapia hormonal e biológica. Quanto mais cedo a doença é diagnosticada, o tratamento tem melhor prognóstico; quando tardio, isto é, a doença já possuir metástases, o 
tratamento proporciona uma melhor qualidade de vida e aumento da sobrevida (INCA, 2020).

Por ser uma doença heterogênea e sensível a diversos tratamentos, necessita de uma abordagem direcionada e baseada em evidência científica. Dentre os diferentes tipos de tratamento, a hormonioterapia tem papel primordial, pois tem um bom perfil de toxicidade, elevada eficácia e inúmeras opções de medicamentos disponíveis (Burstein et al., 2010). A hormonioterapia ou tratamento hormonal é indicado no caso de tumores hormônios sensíveis aos hormônios estrogênio e progesterona, em qualquer estágio da doença, de uso diário e por tempo prolongado (Brasil, 2019b).

O recurso terapêutico hormonal ou hormonioterapia para tratar o câncer de mama baseia-se no uso de substâncias semelhantes ou inibidoras de hormônios já presentes no organismo (Brasil, 2016). Os principais agentes hormonais usados no tratamento desse tipo de câncer são os moduladores seletivos de receptor de estrogênio, como por exemplo o tamoxifeno (age inicialmente como um antiestrogênico, em grau tumoral, precavendo a convergência do estrógeno ao seu receptor), os inibidores de aromatase (bloqueiam a enzima aromatase, encontrada nos músculos, pele, mama e no tecido adiposo, que é usada para converter andrógenos em estrogênio e o fulvestranto (se liga ao respectivo local competindo com o estrogênio no corpo e posteriormente quebra os receptores, evitando assim a resposta celular normal ao estrogênio) (Burstein et al., 2010).

A utilização da hormonioterapia no tratamento do câncer de mama melhora consideravelmente os efeitos da sobrevida a longo prazo. Esse tratamento é proposto para 75 - 80\% dos casos da doença, e quando utilizado em uma fase inicial pode diminuir o risco de recorrência e óbito em 15 anos (Murphy, Bartholomew, Carpentier, Bluethmann \& Vernon 2012). A via de administração desses medicamentos é oral, exceto o fulvestranto, permitindo autonomia do paciente, assegurando melhor condição de vida e bem-estar, oportunizando o controle sobre a terapêutica e tendo menor interferência na vida social (Oliveira \& Queiroz, 2012). Além disso, quando comparado com o tratamento por quimioterapia, possui benefícios como por exemplo a economia de gastos com hospitalizações, equipamentos e recursos humanos (Timmers, 2014).

Diante desse panorama, considera-se importante promover a discussão relacionada ao uso da hormonioterapia no tratamento do câncer de mama, nesta direção, este estudo tem como objetivo apresentar uma revisão integrativa de estudos relacionados a hormonioterapia no tratamento de câncer de mama feminino, elencando estudos que descrevem os efeitos da administração dos medicamentos no organismo e algumas características das pacientes.

\section{Metodologia}

O método utilizado para este estudo trata-se de uma revisão integrativa de literatura que tem por objetivo agrupar e sintetizar as ideias já existentes sobre um dado assunto conforme definido e conceituado em Mendes, Silveira \& Galvão (2008). Após a coleta de dados, é possível analisar e discorrer sobre os achados que contribuem para o enriquecimento da temática, permitindo a observação do conhecimento já produzido e dos aspectos que ainda possuem pouca evidência, norteando pesquisas futuras (Ferreira, 2002; Pompeo \& Rossi, 2009).

Quanto a abordagem, este estudo faz uso da pesquisa qualitativa, definida em Pereira, Shitsuka, Parreira e Shitsuka (2018) como aquela que ocorre em ambiente natural, tendo a subjetividade como seu principal elemento para descrever os fenômenos, além disso, a abordagem qualitativa centra-se no investigador e a análise dos dados segue um processo indutivo.

Em uma revisão integrativa cumprem-se os seguintes estágios: (a) identificação do tema e seleção da hipótese ou questão de pesquisa; (b) estabelecimento de critérios para inclusão e exclusão de estudos/amostragem ou busca na literatura; (c) definição das informações a serem extraídas dos estudos selecionados/categorização dos estudos; (d) avaliação dos estudos incluídos; interpretação dos resultados e apresentação da revisão (Beyea, 1998).

Dessa forma, na primeira etapa, determinou-se que o tema abordaria a terapia hormonal no tratamento de câncer de mama em pacientes do sexo feminino, objetivando responder às seguintes questões de pesquisa: Quais as características individuais e comuns das mulheres com câncer de mama? E os medicamentos utilizados para o tratamento possuem resultado 
satisfatório no tratamento da doença?

Dando sequência às etapas, os critérios de inclusão adotados foram: apresentar o perfil clínico e sociodemográfico de mulheres com câncer de mama e possuir disponibilidade para leitura na íntegra, nos idiomas inglês, português e espanhol. Ademais, optou-se pelo marco temporal de janeiro a dezembro de 2019, por se tratar do período em que a autora trabalhou com mulheres com câncer de mama no estágio curricular da universidade. Os estudos que apresentavam casos de câncer de mama no sexo masculino, e outros artigos de que não se encaixam no tema foram excluídos da pesquisa.

A seleção dos artigos a serem analisados foi realizada em julho de 2020, tendo como banco de dados a Biblioteca Virtual em Saúde (BVS); Web of Science e Scopus. Essas plataformas foram selecionadas por possuir grande importância na área da saúde, bem como, em virtude de sua disponibilidade de artigos relacionados a temática de interesse, realizadas em uma pesquisa prévia.

Foram utilizados os Descritores em Ciências da Saúde (DeCS) e Medical Subject Headings (MeSH) por meio do operador booleano and: "neoplasia da mama" [AND] "inibidores da aromatase"; "neoplasia da mama" [AND]"fulvestranto"; "neoplasia da mama" [AND] "tamoxifeno".

A amostra inicial bruta constitui-se de 2442 artigos, sendo: 856 (Scopus); 757 (Web of Science); 829 (Biblioteca Virtual em Saúde). Após a utilização dos filtros definidos, análise do título, resumo e palavras-chaves e remoção dos duplicados, foram excluídos 2392 artigos. Desta forma restaram 50 artigos, que foram analisados na íntegra através de uma leitura criteriosa, da qual resultou a amostra final, constituída por 23 artigos. A interpretação da busca pode ser analisada no fluxograma de seleção (Quadro 1).

Quadro 1 - Fluxograma de seleção.



Selecionado após a leitura do resumo e na integra: 13

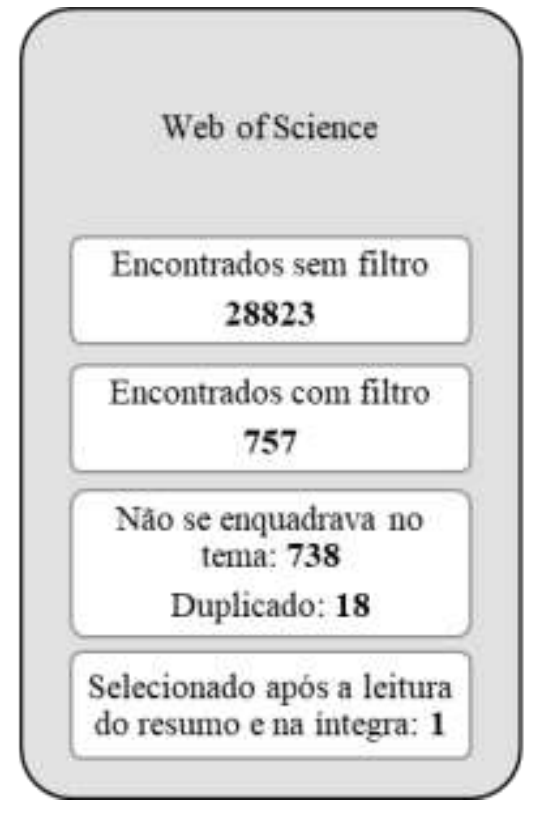

Fonte: Autores.

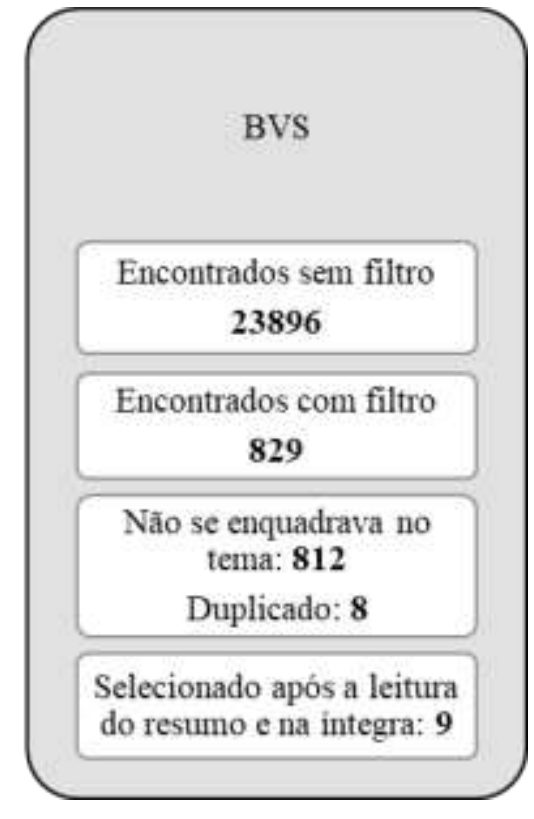

Selecionado após a leitura do resumo e na integra: 9

\section{Resultados e Discussão}

A terapia hormonal no tratamento de câncer mama em pacientes do sexo feminino tem sido abordada de forma ampla na literatura no período analisado. No ano de 2019, das 23 publicações analisadas neste estudo, a maioria delas (22) foi encontrada na língua inglesa, enquanto uma produção em espanhol (1) e nenhuma foi encontrada em português, nas bases de dados pesquisadas. 
Em relação ao tipo de estudo, prevaleceram os estudos do tipo relato de caso (18 artigos), seguidos de estudos de coorte ( 2 artigos), estudos multicêntricos (2) e artigos de revisão sistemática (1 artigo). No que diz respeito aos objetivos dos estudos, usando referenciais teóricos, e metodológicos, os artigos tiveram como foco identificar a eficácia da utilização desses medicamentos em mulheres com câncer de mama, direcionado o foco à efetividade da hormonioterapia e as características das mulheres, quando apresentado.

Os Quadros 2 e 3 mostram a síntese das referências extraídas dos 23 estudos selecionados.

Quadro 2 - Identificação do estudo, autores, fonte de informação, periódico e ano de publicação.

\begin{tabular}{|c|c|c|c|c|c|}
\hline $\mathbf{n}^{\mathbf{o}}$ & Identificação do estudo & Autores & $\begin{array}{l}\text { Fontes de } \\
\text { informação }\end{array}$ & Periódicos & Ano \\
\hline 1 & $\begin{array}{l}\text { ACT-FASTER, a prospective cohort study exploring } \\
\text { patterns of treatment with fulvestrant and } \\
\text { exemestane in postmenopausal patients with breast } \\
\text { cancer positive for advanced hormone receptors in } \\
\text { real life conditions in Germany }\end{array}$ & Maass et al. & Scopus & Breast Care & 2019 \\
\hline 2 & $\begin{array}{l}\text { Association between type of endocrine therapy and } \\
\text { development of estrogen-1 receptor mutations in } \\
\text { patients with advanced hormone-sensitive breast } \\
\text { cancer: a systematic review and meta-analysis of } \\
\text { randomized and nonrandomized studies }\end{array}$ & Najim et al. & Scopus & $\begin{array}{l}\text { Biochimica et } \\
\text { Biophysica } \\
\text { Acta - Cancer } \\
\text { Reviews }\end{array}$ & 2019 \\
\hline 3 & $\begin{array}{l}\text { Fulvestrant } 500 \mathrm{mg} \text { versus Exemestane in } \\
\text { postmenopausal women with metastatic breast } \\
\text { cancer resistant to non-steroidal aromatase adjuvant } \\
\text { inhibitors in clinical practice: a multicenter } \\
\text { retrospective study }\end{array}$ & Xie et al. & Scopus & $\begin{array}{l}\text { Clinical breast } \\
\text { cancer }\end{array}$ & 2019 \\
\hline 4 & $\begin{array}{l}\text { Patterns of treatment and outcome with } 500 \mathrm{mg} \text { of } \\
\text { fulvestrant in postmenopausal women with positive } \\
\text { metastatic breast cancer for hormone receptors / } \\
\text { HER } 2 \text { negative: a multicenter Italian experience in } \\
\text { real life }\end{array}$ & Palumbo et al. & Scopus & $\begin{array}{l}\text { Therapeutic } \\
\text { advances in } \\
\text { medical } \\
\text { oncology }\end{array}$ & 2019 \\
\hline 5 & $\begin{array}{l}\text { Observational multicentre study of Fulvestrant } 500 \\
\text { mg in Japanese postmenopausal women with } \\
\text { advanced or recurrent breast cancer positive for } \\
\text { estrogen receptors after previous endocrine } \\
\text { treatment }\end{array}$ & Kimizuka et al. & Scopus & $\begin{array}{l}\text { Nippon } \\
\text { Medical } \\
\text { School } \\
\text { Journal }\end{array}$ & 2019 \\
\hline 6 & $\begin{array}{l}\text { Efficacy of a CDK4 / } 6 \text { inhibitor in a patient with } \\
\text { breast cancer and liposarcoma: case report and } \\
\text { literature review }\end{array}$ & Loretan et al. & Scopus & Breast Care & 2019 \\
\hline 7 & $\begin{array}{l}\text { Quantitative assays of mRNA expression and } \\
\text { synchronous breast cancer: case report }\end{array}$ & Sorscher, S. & Scopus & $\begin{array}{l}\text { Oncology } \\
\text { Case Reports }\end{array}$ & 2019 \\
\hline 8 & $\begin{array}{l}\text { A rare case: retinal branch vein occlusion associated } \\
\text { with tamoxifen use }\end{array}$ & Demirci et al. & Scopus & $\begin{array}{l}\text { Journal of } \\
\text { Cancer } \\
\text { Research and } \\
\text { Therapeutics }\end{array}$ & 2019 \\
\hline 9 & $\begin{array}{l}\text { Primary antiphospholipid syndrome during treatment } \\
\text { with aromatase inhibitors: case report and literature } \\
\text { review }\end{array}$ & Tenti et al. & Scopus & Medication & 2019 \\
\hline 10 & $\begin{array}{l}\text { Localized adverse skin event induced by anastrozole } \\
\text { as an adjunctive treatment for breast cancer: case } \\
\text { report }\end{array}$ & Tanaka et al. & Scopus & $\begin{array}{l}\text { Dermatology } \\
\text { Case Reports }\end{array}$ & 2019 \\
\hline
\end{tabular}




\begin{tabular}{|c|c|c|c|c|c|}
\hline 11 & $\begin{array}{l}\text { Pure mucinous breast carcinoma with micropapillary } \\
\text { pattern (MUMPC): case report }\end{array}$ & Asano et al. & Scopus & $\begin{array}{l}\text { Oncology } \\
\text { Case Reports }\end{array}$ & 2019 \\
\hline 12 & $\begin{array}{l}\text { Treatment of a patient with breast cancer and } \\
\text { glucose 6-phosphate dehydrogenase deficiency: a } \\
\text { case report }\end{array}$ & Chung et al. & Scopus & Medication & 2019 \\
\hline 13 & $\begin{array}{l}\text { Acute eosinophilic pneumonia induced by tamoxifen } \\
\text { in a patient with breast cancer }\end{array}$ & Kwon et al. & Scopus & $\begin{array}{l}\text { International } \\
\text { Journal of } \\
\text { Surgery Case } \\
\text { Reports }\end{array}$ & 2019 \\
\hline 14 & $\begin{array}{l}\text { A rare case of triple positive metachronic breast } \\
\text { cancer }\end{array}$ & Chhatrala et al. & $\begin{array}{l}\text { Web of } \\
\text { Science }\end{array}$ & $\begin{array}{l}\text { Journal Of } \\
\text { Investigative } \\
\text { Medicine } \\
\text { High Impact } \\
\text { Case Reports }\end{array}$ & 2019 \\
\hline 15 & Fulvestrant-induced toxic epidermal necrolysis. & $\begin{array}{l}\text { Morales-Conde } \\
\text { et al. }\end{array}$ & $\begin{array}{l}\text { Biblioteca } \\
\text { Virtual em } \\
\text { Saúde }\end{array}$ & $\begin{array}{l}\text { An Bras } \\
\text { Dermatol }\end{array}$ & 2019 \\
\hline 16 & $\begin{array}{l}\text { A rare case of jaundice associated with fulvestrants } \\
\text { and hepatotoxicity. }\end{array}$ & $\begin{array}{l}\text { Dziamski, } \\
\text { Konrad M; } \\
\text { Kalakonda, } \\
\text { Aditya; Kohlitz, } \\
\text { Patrick. }\end{array}$ & $\begin{array}{l}\text { Biblioteca } \\
\text { Virtual em } \\
\text { Saúde }\end{array}$ & Am J Ther ; & 2019 \\
\hline 17 & $\begin{array}{l}\text { Sindrome de vasoconstriccion cerebral reversible } \\
\text { asociado a anastrozol: una causa inusual de alto } \\
\text { impacto. / [Reversible cerebral vasoconstriction } \\
\text { syndrome associated with anastrozole: an unusual } \\
\text { cause of high impact]. }\end{array}$ & $\begin{array}{l}\text { Coral-Casas et } \\
\text { al. }\end{array}$ & $\begin{array}{l}\text { Biblioteca } \\
\text { Virtual em } \\
\text { Saúde }\end{array}$ & Rev Neurol ; & 2019 \\
\hline 18 & $\begin{array}{l}\text { Leukocytoclastic vasculitis associated with use of } \\
\text { aromatase inhibitors. }\end{array}$ & $\begin{array}{l}\text { Woodford, } \\
\text { Rachel G; } \\
\text { Becker, Gerrie J; } \\
\text { Jain, Ankit. }\end{array}$ & $\begin{array}{l}\text { Biblioteca } \\
\text { Virtual em } \\
\text { Saúde }\end{array}$ & Intern Med J ; & 2019 \\
\hline 19 & $\begin{array}{l}\text { Long-term survival and complete response to } \\
\text { anastrozole in breast cancer patients with only skin } \\
\text { metastases. }\end{array}$ & Sedloev et al. & $\begin{array}{l}\text { Biblioteca } \\
\text { Virtual em } \\
\text { Saúde }\end{array}$ & $\begin{array}{l}\text { Anticancer } \\
\text { Res; }\end{array}$ & 2019 \\
\hline 20 & $\begin{array}{l}\text { In the case of anastrozole-related hallucinations, can } \\
\text { switching to letrozole be a treatment option? A case } \\
\text { report and literature review }\end{array}$ & $\begin{array}{l}\text { Bozkaya, Yakup; } \\
\text { Erdem, Gökmen } \\
\text { Umut; Demirci, } \\
\text { Nebi Serkan. }\end{array}$ & $\begin{array}{l}\text { Biblioteca } \\
\text { Virtual em } \\
\text { Saúde }\end{array}$ & $\begin{array}{l}\mathrm{J} \quad \text { Oncol } \\
\text { Pharm Pract }\end{array}$ & 2019 \\
\hline 21 & $\begin{array}{l}\text { Retained products of conception in hysteroscopy in a } \\
\text { patient with breast cancer on tamoxifen. }\end{array}$ & $\begin{array}{l}\text { Qadir, Dhilshad; } \\
\text { Chua, Monica; } \\
\text { Sulaiman, } \\
\text { Suzanna. }\end{array}$ & $\begin{array}{l}\text { Biblioteca } \\
\text { Virtual em } \\
\text { Saúde }\end{array}$ & $\begin{array}{l}\text { BMJ Case } \\
\text { Rep }\end{array}$ & 2019 \\
\hline 22 & $\begin{array}{l}\text { Uterine tumor related to tamoxifen similar to ovarian } \\
\text { sex cord tumor (UTROSCT): case report and } \\
\text { literature review of this possible association }\end{array}$ & Segala et al. & $\begin{array}{l}\text { Biblioteca } \\
\text { Virtual em } \\
\text { Saúde }\end{array}$ & $\begin{array}{l}\text { Pathol Res } \\
\text { Pract }\end{array}$ & 2019 \\
\hline 23 & $\begin{array}{l}\text { Case report of atypical endometrial stromal cells in } \\
\text { an endometrial polyp and giant osteoclastic cells in } \\
\text { leiomyoma in the same patient: Is it a coincidence or } \\
\text { is it the result of treatment with tamoxifen? }\end{array}$ & Öztürk et al. & $\begin{array}{l}\text { Biblioteca } \\
\text { Virtual em } \\
\text { Saúde }\end{array}$ & Acta Biomed & 2019 \\
\hline
\end{tabular}

Fonte: Autores. 
Quadro 3 - Apresentação da síntese dos artigos incluídos na Revisão Integrativa: objetivos, métodos, amostra estudada, principais resultados e fármacos utilizados do estudo.

\begin{tabular}{|c|c|c|c|c|c|}
\hline $\mathbf{n}^{\mathbf{0}}$ & Objetivos & Métodos & Amostra estudada & Principais resultados & Fármaco \\
\hline 1 & $\begin{array}{l}\text { Os objetivos primários do } \\
\text { estudo incluíram a eficácia } \\
\text { do fulvestranto de acordo } \\
\text { com a linha de tratamento } \\
\text { paliativo medido pelo } \\
\text { tempo de progressão (TTP) } \\
\text { e dados da vida real sobre a } \\
\text { epidemiologia e o manejo } \\
\text { desses pacientes. }\end{array}$ & $\begin{array}{l}\text { Estudo de } \\
\text { coorte }\end{array}$ & $\begin{array}{l}498 \text { pacientes pós- } \\
\text { menopáusicas } \\
\text { avaliáveis (idade } \\
\text { média de } 67,4 \text { anos } \\
\text { para o fulvestranto e } \\
67,7 \text { anos para o } \\
\text { exemestano) }\end{array}$ & $\begin{array}{l}\text { O fulvestranto e o exemestano } \\
\text { podem ser administrados com } \\
\text { sucesso a pacientes em } \\
\text { condições de rotina e ambos os } \\
\text { medicamentos são bem } \\
\text { tolerados. O TTP foi mais longo } \\
\text { em pacientes tratados com } \\
\text { fulvestranto } 500 \text { mg de primeira } \\
\text { linha em comparação com o de } \\
\text { segunda e terceira linha no } \\
\text { ambiente de cuidados } \\
\text { paliativos. }\end{array}$ & $\begin{array}{ll}\text { Fulvestranto } & \mathrm{e} \\
\text { inibidores } & \mathrm{da} \\
\text { aromatase }\end{array}$ \\
\hline 2 & $\begin{array}{l}\text { O objetivo desta revisão é } \\
\text { estimar o efeito dos } \\
\text { Inibidores da Aromatase } \\
\text { (AIs), Tamoxifeno (TAM) } \\
\text { e Fulvestranto (FUL) no } \\
\text { desenvolvimento } \quad \text { de } \\
\text { mutações receptor } 1 \text { de } \\
\text { estrogênio em câncer de } \\
\text { mama avançado sensível a } \\
\text { hormônios. }\end{array}$ & $\begin{array}{l}\text { Revisão } \\
\text { sistemátic } \\
\text { a de } \\
\text { estudos } \\
\text { qualitativo } \\
\text { s }\end{array}$ & $\begin{array}{l}2362 \text { pacientes acima } \\
\text { de } 18 \text { anos de origem } \\
\text { chinesa em estágio } \\
\text { avançado }\end{array}$ &  & $\begin{array}{l}\text { Fulvestranto, } \\
\text { inibidores da } \\
\text { aromatase } \\
\text { tamoxifeno }\end{array}$ \\
\hline 3 & $\begin{array}{l}\text { O objetivo deste estudo foi } \\
\text { comparar a eficácia e } \\
\text { segurança do fulvestranto } \\
500 \mathrm{mg} \text { e do exemestano na } \\
\text { prática diária. }\end{array}$ & $\begin{array}{l}\text { Estudo } \\
\text { retrospecti } \\
\text { vo } \\
\text { multicêntr } \\
\text { ico }\end{array}$ & $\begin{array}{l}120 \text { pacientes pós- } \\
\text { menopáusicas } \mathrm{ER}+\end{array}$ & $\begin{array}{l}\text { A sobrevida livre de progressão } \\
\text { mediana do grupo que utilizou } \\
\text { o fulvestranto foi } \\
\text { significativamente maior do que } \\
\text { no grupo que utilizou o } \\
\text { exemestano (6,2 meses } \\
\text { [intervalo de confiança de } 95 \% \\
\text { (IC), 5,0-7,4] versus } 4,8 \text { meses } \\
\text { [IC 95\%, 3,0-6,7], P=0,024). }\end{array}$ & $\begin{array}{l}\text { Fulvestranto } \mathrm{e} \\
\text { inibidores } \\
\text { aromatase }\end{array}$ \\
\hline 4 & $\begin{array}{l}\text { Este estudo teve como } \\
\text { objetivo determinar o } \\
\text { desempenho de Ful } 500 \mathrm{mg} \\
\text { e Exe em pacientes } \mathrm{HR}+ \\
\text { HER2 - no câncer de } \\
\text { mama metastático após } \\
\text { progressão da doença com } \\
\text { tratamento adjuvante com } \\
\text { AINE na prática clínica. }\end{array}$ & $\begin{array}{l}\text { Estudo de } \\
\text { coorte } \\
\text { prospectiv } \\
\text { o e } \\
\text { multicêntr } \\
\text { ico }\end{array}$ & $\begin{array}{l}490 \text { mulheres na pós- } \\
\text { menopausa com } \\
\text { metastático HR }+ \\
\text { HER } 2-3\end{array}$ & $\begin{array}{l}\text { A eficácia do F500 foi } \\
\text { detectada em pacientes tratados } \\
\text { tanto na progressão da doença } \\
\text { quanto na manutenção. A } \\
\text { sensibilidade } \\
\text { relevante de } 80 \% \text { dos pacientes } \\
\text { incluídos no estudo } \\
\text { provavelmente poderia explicar } \\
\text { os bons resultados observados } \\
\text { em termos de desfecho. }\end{array}$ & $\begin{array}{l}\text { Fulvestranto } \mathrm{e} \\
\text { inibidores } \\
\text { aromatase }\end{array}$ \\
\hline 5 & $\begin{array}{l}\text { Este estudo teve como } \\
\text { objetivo esclarecer a } \\
\text { eficácia e segurança do } \\
\text { fulvestranto } 500 \mathrm{mg} \text { em } \\
\text { ambientes clínicos. }\end{array}$ & $\begin{array}{l}\text { Estudo } \\
\text { multicêntr } \\
\text { ico, } \\
\text { prospectiv } \\
\text { o e } \\
\text { retrospecti } \\
\text { vo }\end{array}$ & $\begin{array}{l}132 \text { pacientes na pós- } \\
\text { menopausa (idade } \\
\text { mediana de } 66 \text { anos) } \\
\text { com câncer de mama } \\
\text { localmente avançado } \\
\text { ou metastático, que } \\
\text { haviam sido tratadas } \\
\text { com fulvestranto }\end{array}$ & $\begin{array}{l}\text { O TTF mediano foi de } 6,1 \\
\text { meses. OS mediana foi de } 28,5 \\
\text { meses (a data de início foi o } \\
\text { primeiro dia de fulvestranto). } \\
\text { Fulvestranto } 500 \mathrm{mg} \text { é um } \\
\text { tratamento eficaz e seguro para } \\
\text { pacientes com câncer de mama } \\
\text { avançado ou recorrente após } \\
\text { tratamento endócrino prévio. }\end{array}$ & Fulvestranto \\
\hline
\end{tabular}




\begin{tabular}{|c|c|c|c|c|c|}
\hline 6 & $\begin{array}{l}\text { Relatar a eficácia da } \\
\text { aplicação neoadjuvante de } \\
\text { palbociclib e letrozol em } \\
\text { paciente com receptor } \\
\text { invasivo de estrogênio (ER) } \\
+ \text { / HER2- no câncer de } \\
\text { mama e lipossarcoma } \\
\text { concomitante r bem } \\
\text { diferenciado } \\
\text { desdiferenciado } \\
\text { DDLPS) da coxa. }\end{array}$ & $\begin{array}{l}\text { Relato de } \\
\text { caso }\end{array}$ & $\begin{array}{l}\text { Paciente com receptor } \\
\text { invasivo de estrogênio } \\
\text { ER + / HER2- no } \\
\text { câncer de mama e } \\
\text { lipossarcoma } \\
\text { concomitante bem } \\
\text { diferenciado e } \\
\text { desdiferenciado (WD- } \\
\text { DDLPS) da coxa. }\end{array}$ & $\begin{array}{l}\text { Os inibidores de CDK4 / } 6 \\
\text { exibem um alto potencial } \\
\text { terapêutico, embora marcadores } \\
\text { de prognóstico confiáveis } \\
\text { precisem ser identificados. A } \\
\text { paciente também deu } \\
\text { continuidade ao letrozol, com } \\
\text { duração prevista de pelo menos } \\
7 \text { anos. }\end{array}$ & $\begin{array}{ll}\text { Inibidores } & \mathrm{da} \\
\text { aromatase } & \end{array}$ \\
\hline 7 & $\begin{array}{l}\text { Descrever e relatar o caso } \\
\text { de uma mulher com câncer } \\
\text { de mama primário } \\
\text { sincrônico. }\end{array}$ & $\begin{array}{l}\text { Análise } \\
\text { quantitativ } \\
\text { a }\end{array}$ & $\begin{array}{lrr}\text { Uma mulher de } & 60 \\
\text { anos que } & \text { foi } \\
\text { submetida } & & \text { a } \\
\text { mastectomias } & & \\
\text { bilaterais de grau } 1 & \end{array}$ & $\begin{array}{l}\text { A paciente completou } 4 \text { ciclos } \\
\text { de quimioterapia adjuvante com } \\
\text { dose densa de doxorrubicina / } \\
\text { ciclofosfamida seguida por } 12 \\
\text { doses semanais de paclitaxel e, } \\
\text { desde então, ela está tomando } \\
\text { terapia adjuvante com inibidor } \\
\text { da aromatase diariamente sem } \\
\text { evidência de recorrência. }\end{array}$ & $\begin{array}{ll}\text { Inibidores } & \text { da } \\
\text { aromatase } & \end{array}$ \\
\hline 8 & $\begin{array}{l}\text { Relatar o caso de uma } \\
\text { paciente na pré-menopausa } \\
\text { com carcinoma de mama } \\
\text { direito que recebeu terapia } \\
\text { adjuvante com tamoxifeno } \\
\text { ( } 20 \mathrm{mg} / \mathrm{dia} \text { ) por } 1,5 \text { anos e } \\
\text { desenvolveu perda visual } \\
\text { súbita. }\end{array}$ & $\begin{array}{l}\text { Relato de } \\
\text { caso }\end{array}$ & $\begin{array}{l}\text { Um paciente na pré- } \\
\text { menopausa com } \\
\text { carcinoma de mama } \\
\text { do lado direito }\end{array}$ & $\begin{array}{l}\text { O tamoxifeno foi trocado por } \\
\text { um inibidor da aromatase. } \\
\text { Complicações } \\
\text { induzidas por tamoxifeno } \\
\text { devem ser mantidas em mente } \\
\text { quando sintomas visuais são } \\
\text { observados em pacientes } \\
\text { submetidos à terapia com } \\
\text { tamoxifeno. Nesses casos, um } \\
\text { exame ocular completo deve ser } \\
\text { realizado. }\end{array}$ & $\begin{array}{lr}\text { Inibidores } & \text { da } \\
\text { aromatase } & \mathrm{e} \\
\text { tamoxifeno } & \end{array}$ \\
\hline 9 & $\begin{array}{l}\text { Relatar o primeiro caso de } \\
\text { um paciente com síndrome } \\
\text { antifosfolípider primária } \\
\text { (SAF) desenvolvida } \\
\text { durante o tratamento com } \\
\text { anastrazol. }\end{array}$ & $\begin{array}{l}\text { Relato de } \\
\text { caso }\end{array}$ & $\begin{array}{lr}\text { Paciente } & \text { com } \\
\text { síndrome } & \\
\text { antifosfolípide } & \\
\text { primária } & \text { (SAF) } \\
\text { desenvolvida durante } \\
\text { o tratamento com } \\
\text { anastrazol }\end{array}$ & $\begin{array}{l}\text { Um bom controle da doença foi } \\
\text { obtido apesar da continuação do } \\
\text { anastrazol; a situação clínica e } \\
\text { laboratorial do paciente } \\
\text { permaneceu inalterada após a } \\
\text { retirada dos inibidores da } \\
\text { aromatase. }\end{array}$ & $\begin{array}{ll}\text { Inibidores } & \mathrm{da} \\
\text { aromatase } & \end{array}$ \\
\hline 10 & $\begin{array}{l}\text { Descrever um caso raro de } \\
\text { um evento adverso cutâneo } \\
\text { que se desenvolveu em uma } \\
\text { mama afetada por câncer } \\
\text { após o tratamento com um } \\
\text { inibidor de aromatase. }\end{array}$ & $\begin{array}{l}\text { Relato de } \\
\text { caso }\end{array}$ & $\begin{array}{l}\text { Paciente pós- } \\
\text { menopáusica de } 72 \\
\text { anos com diagnóstico } \\
\text { de câncer de mama } \\
\text { em estágio IA }\end{array}$ & $\begin{array}{l}\text { O anastrozol induziu uma } \\
\text { alteração no nível local de } \\
\text { estrogênio, o que afetou as } \\
\text { células endoteliais positivas } \\
\text { para receptores hormonais na } \\
\text { derme próximo à lesão primária } \\
\text { do câncer de mama e causou } \\
\text { um evento adverso cutâneo } \\
\text { apenas na área mencionada. }\end{array}$ & $\begin{array}{ll}\text { Inibidores } & \mathrm{da} \\
\text { aromatase } & \end{array}$ \\
\hline 11 & $\begin{array}{l}\text { Relatar um caso de } \\
\text { carcinoma mucinoso puro } \\
\text { da mama com padrão } \\
\text { micropapilar (MUMPC), } \\
\text { juntamente com uma } \\
\text { revisão da literatura. }\end{array}$ & $\begin{array}{l}\text { Relato de } \\
\text { caso }\end{array}$ & $\begin{array}{l}\text { Uma mulher de } 45 \\
\text { anos foi examinada } \\
\text { para um tumor em sua } \\
\text { mama esquerda. }\end{array}$ & $\begin{array}{l}\text { A quimioterapia adjuvante foi } \\
\text { iniciada após a cirurgia e uma } \\
\text { terapia endócrina foi planejada } \\
\text { (tamoxifeno } 20 \mathrm{mg} \mathrm{/} \mathrm{dia).} \\
\text { Nenhuma } \\
\text { metastática ocorreu até o } \\
\text { momento da elaboração deste } \\
\text { relato de caso, } 3 \text { meses após a } \\
\text { cirurgia. }\end{array}$ & Tamoxifeno \\
\hline
\end{tabular}




\begin{tabular}{|c|c|c|c|c|c|}
\hline 12 & $\begin{array}{l}\text { Relatar o caso de uma } \\
\text { jovem mulher com } \\
\text { deficiência de G6PD em } \\
\text { tratamento seguro contra o } \\
\text { câncer de mama. }\end{array}$ & $\begin{array}{l}\text { Relato de } \\
\text { caso }\end{array}$ & 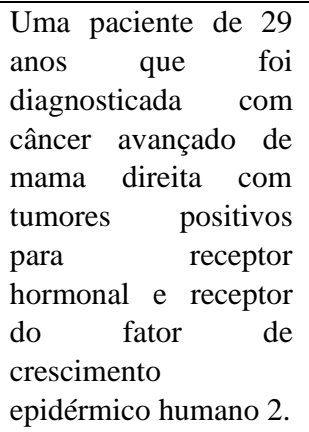 & $\begin{array}{l}\text { O processo de tratamento foi } \\
\text { tranquilo. Não houve evidência } \\
\text { de anemia hemolítica. Exceto } \\
\text { para afrontamentos, o paciente } \\
\text { vive sem efeitos colaterais } \\
\text { notáveis de tratamentos em } \\
\text { andamento ou anteriores. }\end{array}$ & Tamoxifeno \\
\hline 13 & $\begin{array}{l}\text { Descrever o caso de uma } \\
\text { paciente feminina, } 46 \text { anos, } \\
\text { com câncer de mama, } \\
\text { submetida a tratamento } \\
\text { cirúrgico, que apresentou } \\
\text { sintomas respiratórios dois } \\
\text { dias após a administração } \\
\text { de tamoxifeno. }\end{array}$ & $\begin{array}{l}\text { Relato de } \\
\text { caso }\end{array}$ & $\begin{array}{l}\text { Paciente } r \text { feminina } \\
\text { com } 46 \text { anos, com } \\
\text { câncer de mama, } \\
\text { submetida } \\
\text { tratamento cirúrgico. }\end{array}$ & $\begin{array}{l}\text { O tamoxifeno foi considerado a } \\
\text { causa de pneumonia } \\
\text { eosinofílica devido à associação } \\
\text { entre o início da febre e o } \\
\text { horário da primeira } \\
\text { administração de tamoxifeno. O } \\
\text { paciente desenvolveu febre alta } \\
\text { de mais de } 39^{\circ} \mathrm{C} \text { a partir do dia } \\
3 \text { da administração do } \\
\text { tamoxifeno, que cedeu após a } \\
\text { descontinuação do tamoxifeno. }\end{array}$ & Tamoxifeno \\
\hline 14 & $\begin{array}{l}\text { Apresentar um caso raro de } \\
\text { paciente com MCBC triplo } \\
\text { positivo (receptor de } \\
\text { estrogênio, receptor de } \\
\text { progesterona, } \\
\text { positivo) HER-2 } \\
\text { eventualmente desenvolveu } \\
\text { metástase cerebral em } 15 \\
\text { meses, apesar de uma } \\
\text { resposta patológica quase } \\
\text { completa do tumor } \\
\text { primário. }\end{array}$ & $\begin{array}{l}\text { Relato de } \\
\text { caso }\end{array}$ & $\begin{array}{l}\text { Uma mulher } \\
\text { caucasiana de } 33 \text { anos } \\
\text { apresentou carcinoma } \\
\text { ductal invasivo mal } \\
\text { diferenciado (grau 3) } \\
\text { da mama direita em } \\
\text { estádio IIIB } \\
\text { (T4N1M0), que foi } \\
\text { positivo para ER, PR } \\
\text { e HER-2. }\end{array}$ & $\begin{array}{l}\text { Devido ao mau prognóstico, a } \\
\text { família não optou por nenhum } \\
\text { tratamento adicional e o } \\
\text { paciente foi transferido para } \\
\text { cuidados paliativos. }\end{array}$ & Tamoxifeno \\
\hline 15 & $\begin{array}{l}\text { Mostrar o primeiro caso } \\
\text { descrito de necrólise } \\
\text { epidérmica } \\
\text { fulvestranto }\end{array}$ & $\begin{array}{l}\text { Relato de } \\
\text { caso }\end{array}$ & $\begin{array}{lr}\text { Uma mulher de } & 56 \\
\text { anos com história de } \\
\text { carcinoma ductal } \\
\text { mama qu } \\
\text { submetida a } & \text { foi } \\
\text { mastectomia } & \mathrm{e} \\
\text { ressecção } & \text { de } \\
\text { linfonodo } & \text { axilar } \\
\text { ipsilateral } & \end{array}$ & $\begin{array}{l}\text { Cinco dias após a primeira } \\
\text { dose, o paciente apresentou rash } \\
\text { maculopapular que evoluiu para } \\
\text { bolhas e descolamento da } \\
\text { epiderme em mais de } 30 \% \text { da } \\
\text { superfície corporal total. } \\
\text { Fulvestranto foi descontinuado, } \\
\text { tratamento tópico e tratamento } \\
\text { de suporte foram iniciados. }\end{array}$ & Fulvestranto \\
\hline 16 & $\begin{array}{l}\text { Demonstrar } r \text { uma } \\
\text { apresentação aguda e rara } \\
\text { de hepatotoxicidade } \\
\text { clinicamente evidente após } \\
\text { o tratamento com } \\
\text { fulvestranto. }\end{array}$ & $\begin{array}{l}\text { Relato de } \\
\text { caso }\end{array}$ & $\begin{array}{l}\text { Uma mulher de } 65 \\
\text { anos com estágio IV }\end{array}$ & 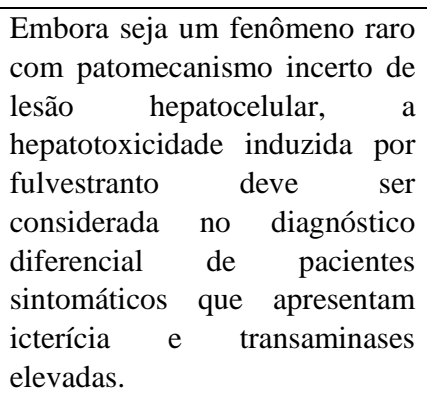 & Fulvestranto \\
\hline 17 & $\begin{array}{l}\text { Relatar o caso de uma } \\
\text { mulher com histórico de } \\
\text { câncer } \\
\text { originalmente tratado com }\end{array}$ & $\begin{array}{l}\text { Relato de } \\
\text { caso }\end{array}$ & $\begin{array}{l}\text { Mulher de } 71 \text { anos } \\
\text { com história de câncer } \\
\text { de } \\
\text { originalmente } \\
\text { tratada }\end{array}$ & $\begin{array}{l}\text { Na admissão, apresentou três } \\
\text { eventos com as mesmas } \\
\text { características, que exigiram } \\
\text { monitorização intensiva e dois }\end{array}$ & $\begin{array}{lr}\text { Inibidores } & \text { da } \\
\text { aromatase } & \mathrm{e} \\
\text { tamoxifeno } & \end{array}$ \\
\hline
\end{tabular}




\begin{tabular}{|c|c|c|c|c|c|}
\hline & $\begin{array}{l}\text { tamoxifeno, que foi } \\
\text { internada por afasia, } \\
\text { sonolência e uma dor de } \\
\text { cabeça em trovoada e teve } \\
\text { diagnóstico de RCVS mais } \\
\text { SAH associado ao uso de } \\
\text { anastrozol. }\end{array}$ & & $\begin{array}{l}\text { com tamoxifeno. } \\
\text { Devido à urticária, o } \\
\text { manejo do anastrozol } \\
\text { foi escalonado. }\end{array}$ & $\begin{array}{l}\text { panangiogramas terapêuticos } \\
\text { com nimodipino intra-arterial, } \\
\text { com posterior resolução do } \\
\text { vasoespasmo. }\end{array}$ & \\
\hline 18 & $\begin{array}{l}\text { Apresentar um caso } \\
\text { vasculite leucocitoclástica e } \\
\text { comparar as características } \\
\text { dos pacientes e a trajetória } \\
\text { da doença, a fim de auxiliar } \\
\text { na identificação e } \\
\text { tratamento precoces. }\end{array}$ & $\begin{array}{l}\text { Relato de } \\
\text { caso }\end{array}$ & $\begin{array}{l}\text { Paciente que faz uso } \\
\text { de inibidores da } \\
\text { aromatase }\end{array}$ & $\begin{array}{l}\text { A vasculite leucocitoclástica é } \\
\text { uma complicação incomum, } \\
\text { mas importante, do uso de } \\
\text { inibidores da aromatase, que } \\
\text { pode ter ramificações } \\
\text { cosméticas e sistêmicas. }\end{array}$ & $\begin{array}{ll}\text { Inibidores } & \text { da } \\
\text { aromatase } & \end{array}$ \\
\hline 19 & $\begin{array}{l}\text { Demonstrar o excelente } \\
\text { resultado terapêutico após } \\
\text { terapia endócrina apenas } \\
\text { em câncer de mama com } \\
\text { envolvimento apenas da } \\
\text { pele. }\end{array}$ & $\begin{array}{l}\text { Relato de } \\
\text { caso }\end{array}$ & $\begin{array}{l}\text { Uma mulher de } 82 \\
\text { anos sem história } \\
\text { familiar de câncer de } \\
\text { mama }(\mathrm{CM}) \text {, que foi } \\
\text { diagnosticada com } \\
\text { CM lobular invasivo } \\
\text { metastático de novo } \\
\text { para receptor de } \\
\text { estrogênio r / } \\
\text { progesterona e HER2 } \\
\text { negativo. }\end{array}$ & $\begin{array}{l}\text { Este é o único caso de } \\
\text { colesterol lobular com } \\
\text { manifestação metastática de } \\
\text { novo como metástases cutâneas } \\
\text { múltiplas, que atingiram } \\
\text { resposta clínica completa após o } \\
\text { tratamento com inibidor da } \\
\text { aromatase (anastrozol) com } \\
\text { sobrevida global impressionante } \\
\text { em longo prazo. }\end{array}$ & $\begin{array}{ll}\text { Inibidores } & \text { da } \\
\text { aromatase } & \end{array}$ \\
\hline 20 & $\begin{array}{l}\text { Enfatizar que efeitos } \\
\text { colaterais neurológicos } \\
\text { como alucinação podem } \\
\text { ocorrer raramente durante o } \\
\text { tratamento com anastrozol } \\
\text { e em caso de alucinações } \\
\text { relacionadas ao inibidor da } \\
\text { aromatase, a troca para } \\
\text { outro inibidor da aromatase } \\
\text { (letrozol) pode ser uma } \\
\text { opção de tratamento. }\end{array}$ & $\begin{array}{l}\text { Relato de } \\
\text { caso }\end{array}$ & $\begin{array}{l}\text { Uma mulher de } 62 \\
\text { anos com câncer de } \\
\text { mama desenvolveu } \\
\text { alucinações } \\
\text { repetitivas nos dias } \\
\text { seguintes ao início do } \\
\text { anastrozol }\end{array}$ & 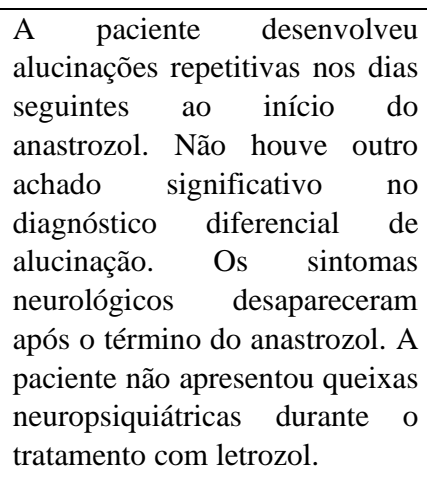 & $\begin{array}{l}\text { Inibidores } \\
\text { aromatase }\end{array}$ \\
\hline 21 & $\begin{array}{l}\text { Apresentar o caso de uma } \\
\text { mulher chinesa de } 47 \text { anos } \\
\text { com câncer de mama em } \\
\text { uso de tamoxifeno, que } \\
\text { apresentou um episódio de } \\
\text { sangramento vaginal } \\
\text { intenso após } 2 \text { anos de } \\
\text { amenorreia. }\end{array}$ & $\begin{array}{l}\text { Relato de } \\
\text { caso }\end{array}$ & $\begin{array}{l}\text { Uma mulher chinesa } \\
\text { de } 47 \text { anos com } \\
\text { câncer de mama em } \\
\text { uso de tamoxifeno }\end{array}$ & $\begin{array}{l}\text { Seu teste de urina para gravidez } \\
\text { deu negativo e a } \\
\text { ultrassonografia suspeitou de } \\
\text { malignidade. Ela foi submetida } \\
\text { a uma avaliação histeroscópica } \\
\text { para sangramento anormal com } \\
\text { tamoxifeno. A histopatologia } \\
\text { confirmou os produtos da } \\
\text { concepção. }\end{array}$ & Tamoxifeno \\
\hline 22 & $\begin{array}{l}\text { Representar mais uma } \\
\text { evidência da possível } \\
\text { associação entre a terapia } \\
\text { com Tamoxifeno e } \\
\text { UTROSCT, descrevendo } \\
\text { um caso adicional ocorrido } \\
\text { em uma paciente de } 62 \\
\text { anos de idade submetida a } \\
3 \text { anos de terapia com } \\
\text { Tamoxifeno } \\
\text { carcinoma de } \\
\text { bilateral para }\end{array}$ & $\begin{array}{l}\text { Relato de } \\
\text { caso }\end{array}$ & $\begin{array}{l}\text { Uma paciente de } 62 \\
\text { anos de idade } \\
\text { submetida a terapia } \\
\text { com Tamoxifeno por } \\
3 \text { anos para carcinoma } \\
\text { de mama bilateral. }\end{array}$ & $\begin{array}{l}\text { O presente trabalho representa } \\
\text { mais uma evidência da possível } \\
\text { associação entre a terapia com } \\
\text { tamoxifeno e UTROSCT. }\end{array}$ & Tamoxifeno \\
\hline
\end{tabular}




\begin{tabular}{|c|c|c|c|c|c|}
\hline 23 & $\begin{array}{l}\text { Apresentar o caso de uma } \\
\text { paciente com câncer de } \\
\text { mama que iniciou o } \\
\text { tratamento rem } \\
\text { Tamoxifeno apresentando } \\
\text { formação de células } \\
\text { estromais atípicas em um } \\
\text { pólipo endometrial e } \\
\text { células osteoclásticas } \\
\text { semelhantes a células } \\
\text { gigantes no leiomioma do } \\
\text { útero. }\end{array}$ & $\begin{array}{l}\text { Relato de } \\
\text { caso }\end{array}$ & $\begin{array}{lcc}\text { Uma } & \text { mulher } & \text { de } 53 \\
\text { anos, de } & \text { origem } \\
\text { caucasiana } & \end{array}$ & $\begin{array}{l}\text { O tamoxifeno levou a reações } \\
\text { estromais, como observamos } \\
\text { neste caso. O comprometimento } \\
\text { do tamoxifeno pode levar ao } \\
\text { desenvolvimento de células } \\
\text { estromais atípicas no pólipo } \\
\text { endometrial e osteoclásticas } \\
\text { como células gigantes no } \\
\text { leiomioma. }\end{array}$ & Tamoxifeno \\
\hline
\end{tabular}

Fonte: Autores.

De acordo com o INCA a incidência do câncer de mama tende a crescer progressivamente a partir dos 40 anos (INCA, 2020c; INCA, 2020a). Na população feminina abaixo de 40 anos, ocorrem menos de 10 óbitos a cada 100 mil mulheres, enquanto na faixa etária a partir de 60 anos o risco aumenta em até 10 vezes (INCA, 2020a).

A idade é um dos mais importantes fatores de risco para a doença (cerca de quatros em cada cinco casos ocorrem após os 50 anos) (INCA, 2020b). As indicações aos medicamentos abordados neste estudo, baseadas em consensos e diretrizes atualizadas, recomendam para mulheres na pré-menopausa com tumor endócrino-positivo o uso do tamoxifeno por cinco anos como tratamento padrão. Para esse grupo está contraindicado o uso dos inibidores da aromatase, salvo se a paciente tem história trombofílica (Goldhirsch et al., 2007; Goldhirsch et al,, 2011).

Para mulheres na pós-menopausa, anteriormente, havia indicação por parte de um grupo de especialistas de trocar para os inibidores da aromatase após dois a três anos de uso do tamoxifeno, a depender de avaliação da densidade óssea, devido ao aumento do risco de perda óssea associado ao tratamento (Goldhirsch et al., 2007; Goldhirsch et al. 2009).

Ademais foi possível observar que as pacientes em que foi administrado o fulvestranto encontravam-se na pósmenopausa e com o câncer de mama em estágio mais avançado. Entretanto observou-se também que foi administrado esta terapia hormonal em mulheres acima dos 18 anos. As pacientes que fizeram uso dos inibidores da aromatase estavam dentro da faixa etária dos 47 aos 82 anos, geralmente na pós-menopausa. Em um estudo de caso a paciente estava na pré-menopausa.

Já o tamoxifeno também pode ser usado em mulheres que ainda não atingiram a menopausa. Nos estudos descritos nesta revisão foi possível assinalar que as pacientes em uso deste medicamento foram mulheres na faixa etária de 29 aos 71 anos (Chung, Hsu, Chen \& Hsu, 2019; Coral-Casas, 2019). É recomendado que mulheres em pré-menopausa, em uso de tamoxifeno, apenas os cuidados ginecológicos de rotina devem ser tomados, pois este grupo não apresenta risco aumentado. Já as mulheres na pós-menopausa, em uso de tamoxifeno, devem ser monitorizadas rigorosamente para sintomas ou sinais de hiperplasia ou câncer endometrial (Acog committee opinion, 2006).

\subsection{Fulvestranto}

O fulvestranto é um medicamento que trata o câncer de mama metastático positivo para receptores hormonais, foram citados em 30,43\% (7) dos artigos selecionados para o estudo (fulvestranto e/ou associado e/ou substituído por outro (s) hormônio (s)). Baseado nos artigos de Palumbo et al. (2019). e Kimizuka et al. (2019) publicados em 2019, foi possível verificar a eficácia do fulvestranto, principalmente em mulheres pós-menopausa com câncer de mama avançado ou recorrente após tratamento hormonal prévio.

Além disso, o fulvestranto possui destaque entre outros medicamentos, como demonstrado em estudo retrospectivo multicêntrico, onde a eficácia deste medicamento obteve maior êxito em comparação ao exemestano, sendo possível observar que houve sobrevida livre de progressão mediana (PFS) significativamente maior nos pacientes que utilizaram o fulvestranto 
quando comparado com os pacientes que utilizaram o exemestano (Xie et al., 2019).

No estudo de coorte realizado por Maass et al. (2019), o fulvestranto também obteve êxito em casos de pacientes em cuidados paliativos, onde foi verificado um tempo de progressão maior em pacientes que utilizaram o fulvestranto $500 \mathrm{mg} \mathrm{em}$ primeira linha de tratamento, podendo ser administrado de forma segura em situações rotineiras.

Embora não seja um medicamento muito utilizado em associações, o fulvestranto é conhecido como uma terapia sistêmica segura e efetiva, servindo como opção no método para mulheres com câncer de mama, principalmente no período posterior a menopausa (Lee, Goodwin \& Wilcken, 2017). No entanto, o fulvestranto apresenta também aspectos negativos, como nos casos em que houve presença de efeitos adversos. Esse medicamento foi descontinuado, devido a ocorrência de necrólise epidérmica tóxica em uma paciente, que é descrita como uma reação cutânea grave, que acomete a pele e a membrana mucosa, doença de emergência médica com potencial de morbidade e mortalidade altas (Ghislain \& Roujeau, 2002).

Além disso, nesta revisão 8,69\% (2) dos estudos demonstraram outras ocorrências de efeitos adversos raros, como por exemplo, mutação genética, hepatotoxicidade e icterícia. Os efeitos mais comuns relatados pelas pacientes incluíram a presença de dispneia, bronquite e mudanças gastrointestinais como náuseas e vômitos (Robertson et al., 2016; Boér, 2017).

\subsection{Inibidores da Aromatase}

Os inibidores da aromatase são uma classe de fármacos que bloqueiam a enzima aromatase, sendo usados para o tratamento do câncer de mama, referido como escolha em 56,52\% (13) dos artigos da presente revisão.

Colozza, Califano, Minenza, Dinh e Azambuja (2008), indicaram a utilização preferencial do anastrozol em substituição ao tamoxifeno no tratamento adjuvante de mulheres com câncer de mama após a menopausa. Neste estudo foi observado a substituição de algum tipo da terapia hormonal presente por um inibidor de aromatase (Demirci, 2019).

A terapia com um inibidor da aromatase em associação com outro medicamento (inibidor da CDK4) resultou em efeito benéfico, relatado por Loretan, Moskovszky e Kurrer (2019), foi possível verificar que, após quatro semanas de administração desses fármacos já houve redução de $20 \%$ no volume do sarcoma, levando a um bom prognóstico de sua utilização.

Os inibidores da aromatase obtiveram sucesso no tratamento do câncer de mama metastático. O estudo de Sedloev et al. (2019), descreve a administração de anastrazol em eventos de câncer na pele, decorrente do local inicial, a mama. Após a realização do tratamento por 116 semanas a paciente obteve uma resposta clínica completa.

Estudos demonstraram que tratamento hormonal com inibidores da aromatase possui falhas no controle da doença, corroborando com diversos efeitos adversos, como por exemplo, mutação genética, evento adverso cutâneo localizado, síndrome de vasoconstrição cerebral reversível, vasculite leucocitoclástica e alucinações (Tenti, Giordano, Cutolo, Giannini \& Fioravanti, 2019; Tanaka et al., 2019; Coral-Casas et al., 2019; Woodford, Becker \& Jain, 2019; Bozkaya, Erdem \& Demirci, 2019).

Foi verificado que o uso de inibidores da aromatase podem desencadear respostas autoimunes. $\mathrm{O}$ estudo de Tenti et al. (2019), explicitam a ocorrência de síndrome fosfolipídica primária em uma paciente com câncer de mama em tratamento com inibidor da aromatase.

Alguns efeitos adversos mais frequentes incluem distúrbios gastrointestinais, como náusea, vômitos e diarreia (Buzdar et al, 1997). Também podem ocorrer efeitos neurológicos, dentre eles a cefaleia, sonolência, confusões mentais, paralisia motora, convulsões e em casos raros, produzir um estado de depressão e coma (Barros et al., 2000). 


\subsection{Tamoxifeno}

O tamoxifeno é um modulador seletivo do receptor de estrógeno, no câncer de mama é um antagonista do receptor de estrogênio. É um fármaco administrado por via oral, que possui um papel importante para que haja o sucesso do tratamento (Perrone et al., 2015). As reações obtidas durante o tratamento com o tamoxifeno e/ou associado foram citadas em 47,82\% (11 artigos) da pesquisa. Em um caso ele foi usado como tratamento adjuvante com a quimioterapia (Asano et al., 2019).

Em 2019, Asano et al. (2019) e Chung et al. (2019), comprovaram a eficácia do tratamento com tamoxifeno descrevendo alguns resultados satisfatórios. No estudo realizado por Chung et al. (2019) a paciente é portadora de uma deficiência de G6PD (glicose-6-fosfato desidrogenase) e por realizar o tratamento com tamoxifeno pode manter sua rotina sem efeitos colaterais aparentes.

Devido a efeitos adversos, as pacientes pararam de realizar o tratamento com tamoxifeno, e os achados são descrito em dois estudos. No estudo de Demirci et al. (2019) (relato de caso), a paciente parou de realizar o tratamento com o tamoxifeno devido a complicações oculares, alterando o tratamento para os inibidores da aromatase. As reações tóxicas oculares são raras após o uso do tamoxifeno, consistindo de retinopatia cristalina, depósitos corneanos, neurite óptica e edema macular cistóide.

A retinopatia e a ceratopatia têm sido relatadas em pacientes tratados com altas doses e por longo período de tempo (Pavilidis et al., 1992; Noureddin et al., 1999). Já no relato de caso de Kwon, Kim, Choi, Park \& Kim (2019), o tamoxifeno foi considerado causa de pneumonia eosinofílica. Têm-se demonstrado que os tratamentos atualmente preconizados para câncer de mama, incluindo tamoxifeno, aumentam o risco de pneumonite intersticial, especialmente quando combinados a radioterapia adjuvante (Christensen et al., 2008).

Ainda é possível associar a utilização do tamoxifeno como um dos fatores causadores do tumor uterino semelhante a tumor de cordão sexual ovariano (UTROSCT) (Segala et al, 2019). Além disso, o tamoxifeno pode aumentar a incidência de lesões endometriais em outros tecidos, como o ósseo e o uterino, no entanto, a grande maioria não evolui para outro câncer (Deligdisch et al., 2000).

Outros efeitos colaterais já conhecidos pelo uso do tamoxifeno incluem os eventos tromboembólicos, artralgias, acidentes vasculares cerebrais isquêmicos, fogachos, cefaleia e aumento do risco de sarcomas uterinos (Visvanathan et al., 2009).

Assim como em outros medicamentos, a utilização da terapia hormonal possui riscos, que podem variar conforme sua administração e orientação (tempo de uso, dosagem, via de administração, classificação do fármaco, entre outros. Dessa forma é necessário que a prescrição do medicamento leve em consideração as características individuais a paciente, bem como, a atualização das evidências científicas já relatadas, para que a partir disso, seja obtido um melhor prognóstico proporcionando melhores benefícios (Whitmer, Quesenberry, Zhou \& Yaffe, 2011) para as pacientes.

\section{Conclusão}

No cenário atual sobre a terapia hormonal, os fármacos tamoxifeno, fulvestranto e os inibidores da aromatase poderão ter um papel relevante para o tratamento de mulheres com câncer de mama, considerando seu mecanismo de ação e a sua eficácia diferenciada em relação aos outros tipos de tratamento de câncer de mama.

A terapia hormonal prevaleceu-se em pacientes que se encontravam pós-menopáusicas, e em alguns casos, observouse que eram utilizados como adjuvantes e o risco de descontinuidade à hormonioterapia foi associado aos efeitos adversos durante o tratamento realizado.

Os estudos realizados até o momento apontam para vantagens do fulvestranto em relação aos demais, tendo em vista que ele é medicamento intravenoso. No entanto, cabe ressaltar que os medicamentos estudados possuem diversos efeitos 
colaterais.

Para avaliar se a hormonioterapia é eficaz em qualquer classe e as vantagens que podem oferecer para a qualidade de vida, necessitam ser consideradas em conjunto com os riscos para a saúde e os recursos (custos) associados ao uso, sendo necessário a continuidade de estudos neste campo para compreender a eficácia da hormonioterapia nestas pacientes.

Pelo caráter de base secundária deste estudo, não foi possível avaliar algumas questões importantes relacionadas às pacientes, tais como a classificação dos tumores malignos da mama e o estágio em que se encontrava, em todas as literaturas escolhidas.

Com a realização do estudo esperou-se levantar dados que possibilitem o estabelecimento de planos de ação futuras visando contribuir de forma significativa para a qualidade na assistência farmacêutica.

A partir desse estudo, foi possível verificar que muitos fatores influenciam na resposta hormonal, tais como: a interação medicamentosa, o estilo de vida e fatores hereditários. Além disso, sobrevêm repercussões negativas desses hormônios no organismo e consequentemente no dia-a-dia das mulheres em tratamento. É premente ampliar estudos com intuito de analisar as variáveis que interferem na eficácia e, condutas no tratamento. Afinal, aumentar os índices de adesão e persistência ao tratamento e, portanto, diminuir os riscos de resultados negativos e redução de gastos são aspectos necessários para nortear os cuidados desses pacientes.

\section{Agradecimentos}

Agradecemos ao professor Phd Sandro R. P. da Rocha, diretor do Pharmaceutical Engineering - School of Pharmacy, Department of Pharmaceutics \& Chemical and Life Science Engineering, Massey Cancer Center, que gentilmente revisou o texto do resumo em língua inglesa de nosso trabalho.

\section{Referências}

Acog Committee Opinion. (2006). No. 336: Tamoxifen and uterine cancer. Obstet Gynecol. 107 (6): 1475-8.

Asano, Y., Kashiwagi, S., Nagamori, M., Tanaka, S., Kuwae, Y., Amano, R., \& Ohira, M. (2019). Pure mucinous breast carcinoma with micropapillary pattern (MUMPC): case report. Oncology Case Reports; 12 (2): 554-59.

Barros, M.A. et al. (2000) Efeitos colaterais em quimioterapia: complicações neurológicas. Bases da enfermagem em quimioterapia. Lemar, $340-350,2000$.

Beyea, S. C., Nicoll, L. H. (1998). Writing an integrative review. AORN J. 67 (4): 877-80.

Brasil. (2019a). Estadiamento. Instituto Nacional de Câncer.

Brasil. (2019b). Departamento de Regulação, Avaliação e Controle/Coordenação Geral de Sistemas de Informação. Secretaria de Atenção à Saúde.

Brasil. (2016). Tratamento pelo Sistema Único de Saúde. Instituto Nacional de Câncer.

Bozkaya, Y., Erdem, G. U., \& Demirci, N. S. (2019). In the case of anastrozole-related hallucinations, can switching to letrozole be a treatment option? A case report and literature review. J Oncol Pharm Pract. 25 (3): 754-57.

Boér, K. (2017). Fulvestrant in advanced breast cancer: evidence to date and place in therapy. Therapeutic advances in medical oncology, 9 (7): $465-79$.

Buzdar, A. U., Jones, S. E., Vogel, C. L., Wolter, P., \& Webster, A. (1997). A phase III trial comparing anastrozole (1 and 10 milligrams), a potent and selective aromatase inhibitor, with megestrol acetate in postmenopausal women with advanced breast carcinoma. Arimidex Study Group. Cancer. 79 (4): 730 9.

Burstein, H. J., Prestrud, A. A., Seidenfeld, J., Anderson, H., Buchholz, T. A., Davidson, N. E., \& Griggs, J. J. (2010). American society of clinical oncology clinical practice guideline: update on adjuvant endocrine therapy for women with hormone receptor-positive breast cancer. J Clin Oncol 2010; 28 (23): 3784 96.

Cantinelli, F. S., Camacho, R. S., Smaletz, O., Gonsales, B. K., Braguittoni E, \& Jr, J. R. (2006). A oncopsiquiatria no câncer de mama: considerações a respeito de questões do feminino. Rev. psiquiatr. clín. 2006 (São Paulo); 33 (3): 124-133.

Chhatrala, H. S., Khuu, J., \& Zuberi, L. (2019). A rare case of triple positive metachronic breast cancer. J Investig Med High Impact Case Rep. 2324709619892106. 
Chung, W., Hsu, Y., Chen, Y., \& Hsu, H. (2019). Treatment of a patient with breast cancer and glucose 6-phosphate dehydrogenase deficiency: a case report. Medication, 98 (13): e14987.

Colozza, M., Califano, R., Minenza, E., Dinh, P., \& Azambuja, E. (2008). Aromatase inhibitors: a new reality for the adjuvant endocrine treatment of earlystage breast cancer in postmenopausal women. Mini Rev Med Chem; 8 (6): 564-74.

Coral-Casas, J., Ricaurte-Fajardo, A., McCormick, S. J., Baracaldo, I., Jimenez, C. A., \& Mejia, J. A. (2019). Sindrome de vasoconstriccion cerebral reversible asociado a anastrozol: una causa inusual de alto impacto. / [Reversible cerebral vasoconstriction syndrome associated with anastrozole: an unusual cause of high impact]. Rev Neurol; 68 (6): 250-54.

Christensen, S., Pedersen, L., Grijota, M., Kornum, J. B., Beiderbeck, A., \& Sørensen, H.T. (2008). Incidence of interstitial pneumonitis among breast cancer patients: a 10-year Danish population-based cohort study. Br J Cancer. 98 (11): 1870-75.

Dziamski, K.M., Kalakonda, A., \& Kohlitz, P. (2019). A rare case of jaundice associated with fulvestrants and hepatotoxicity. Am J Ther. 26 (1): e122-e123.

Deligdisch, L., Kalir, T., Cohen, C.J., Latour, M., Bouedec, G.L., \& Penault-Llorca, F. (2000). Endometrial histopathology in 700 patients treated with tamoxifen for breast cancer. Gynecol Oncol. 78 (2): 181-6.

Demirci, N.S., Erdem, G.U., Uçgun, N.I., Bozkaya, Y., Ozdemir, N.Y., Dogan, M., \& Zengin, N. (2019). A rare case: retinal branch vein occlusion associated with tamoxifen use. Journal of Cancer Research and Therapeutics, 15 (3): 722-24.

Ferreira, N.S.A. (2002). As pesquisas denominadas “estado da arte”. Educ Soc. 2002; 23 (79): 257-72.

Globocan. (2018). Globocan 2018: carga global do câncer. OncoNews Informação e Evidência. 2018.

Ghislain, P.D., Roujeau, J.C. (2002). Treatment of severe drug reactions: Stevens-Johnson syndrome, toxic epidermal necrolysis and hypersensitivity syndrome. Dermatol Online J. 2002 Jun; 8 (1): 5.

Goldhirsch, A., Wood, W.C., Gelber, R.D., Coates, A.S., Thürlimann, B., \& Senn, H.J. (2007). Gallen conference. Progress and promise: highlights of the International Expert Consensus on the Primary Therapy of Early Breast Cancer 2007. Ann Oncol. 2007 Jul; 18 (7): 1133-44.

Goldhirsch, A., Wood, W.C., Gelber, R.D., Coates, A.S., Thürlimann, B., \& Senn, H.J. (2011). Strategies for subtypes--dealing with the diversity of breast cancer: highlights of the St. Gallen International Expert Consensus on the Primary Therapy of Early. Breast Cancer 2011. Ann Oncol. 2011 Ago; 22 (8): 173647.

Goldhirsch, A., Ingle, J.N., Gelber, R.D., Coates, A.S., Thürlimann, B., \& Senn, H.J. (2009). Thresholds for therapies: highlights of the St. Gallen International Expert Consensus on the Primary Therapy of Early Breast Cancer 2009. Ann Oncol. 2009 Ago; 20 (8): 1319-29.

Haddad, C.F. (2010). Trastuzumab no câncer de mama. Revista Femina 2010; 38 (2): 74-78.

INCA. (2019). Rio Grande do Sul e Porto Alegre: estimativa dos casos novos. Rio de Janeiro: Instituto Nacional de Câncer, 2019.

INCA. (2020b). Câncer de mama. Rio de Janeiro: Instituto Nacional de Câncer, 2020b.

INCA. (2011). ABC do câncer: abordagens básicas para o controle do câncer. Rio de Janeiro: Instituto Nacional de Câncer, 2011.

INCA. (2020c). Estimativa 2020: incidência de câncer no Brasil. Rio de Janeiro: Instituto Nacional de Câncer, 2020c.

INCA. (2020a). Atlas de Mortalidade por Câncer. Rio de Janeiro: Instituto Nacional de Câncer, 2020a.

Jager, J.J., Keymeulen, K., Beets-Tan, R.G.H., Hupperets P., Kroonenburgh, M., Houben, R., Ruysscher, D., Lambin, P., \& Boersma, L.J. (2010). FDG-PETCT for staging of high-risk breast cancer patients reduces the number of further examinations: a pilot study. Acta Oncol.; 9 (2): 185-91, 2010.

Kimizuka, K., Inoue, K., Nagai, S.E., Saito, T., Nakano, S., Futsuhara, K., ..., \& Kurosumi, M. (2019). Observational multicentre study of Fulvestrant 500 mg in Japanese postmenopausal women with advanced or recurrent breast cancer positive for estrogen receptors after previous endocrine treatment. Nippon Medical School Journal 2019; 86 (3): 165-71.

Kwon, E., Kim, M., Choi, E., Park, Y., \& Kim, C. (2019). Acute eosinophilic pneumonia induced by tamoxifen in a patient with breast cancer. International Journal of Surgery Case Reports 2019; 60: 186-90.

Lee, C.I., Goodwin, A., \& Wilcken, N. (2017). Fulvestrant for hormone-sensitive metastatic breast cancer. Cochrane Database Syst Rev. 2017 Jan; 2017 (1): CD011093.

Loretan, L., Moskovszky, L.E., Kurrer, M., Exner, G.U., \& Trojan, A. (2019). Efficacy of a CDK4 / 6 inhibitor in a patient with breast cancer and liposarcoma: case report and literature review. Breast Care 2019; 14 (5): 325-28.

Maass, N., Ostermann, H., Possinger, K., Klein, P., Tesch, H., Mühlenhoff, L., \& Dirk Bauerschlag, D. (2019). ACT-FASTER, a prospective cohort study exploring patterns of treatment with fulvestrant and exemestane in postmenopausal patients with breast cancer positive for advanced hormone receptors in real life conditions in Germany. Breast Care (Basel) 2019 Dez; 14 (6): 401-408.

Mendes, K.D.S., Silveira, R.C.C.P., \& Galvão, C.M. (2008). Revisão integrativa: método de pesquisa para a incorporação de evidências na saúde e na enfermagem integrative literature. Texto \& Contexto Enferm, (Florianópolis) 2008 Out/Dez; 17 (4): 758-64.

Morales-Conde, M., López-Ibáñez, N., \& Calvete-Candenas, J. (2019). Fulvestrant-induced toxic epidermal necrolysis. A. Bras. Dermatol. 2019 (Rio de Janeiro); 94 (2): 218-20. 
Murphy, C.C., Bartholomew, L.K., Carpentier, M.Y., Bluethmann, S.M., \& Vernon, S.W. (2012). Adherence to adjuvant hormonal therapy among breast cancer survivors in clinical practice: a systematic review. Breast Cancer Res Treat. 2012 Jul; 134 (2): 459-78.

Najim, O., Seghers, S., Sergoynne, L., Gaver, H.V., Papadimitriou, K., Wouters, K., Trinh, X.B., Huizing, M.T., \& Tjalma, W. (2019). The association between type of endocrine therapy and development of estrogen receptor-1 mutation(s) in patients with hormone-sensitive advanced breast cancer: A systematic review and meta-analysis of randomized and non-randomized trials. Biochim Biophys Acta Rev Cancer 2019 Dez; 1872 (2): 188315.

Noureddin, B.N., Seoud, M., Bashshur, Z., Salem, Z., Shamseddin, A., \& Khalil, A.. Ocular Toxicity in low - dose tamoxifen: a prospective study. Eye. 1999 Dez; 13 (6): 729-33.

Oliveira, A.T., \& Queiroz, A.P. (2012). Perfil de uso da terapia antineoplásica oral: a importância da orientação farmacêutica. Rev Bras Farm Hosp Serv Saúde 2012 (São Paulo); 3 (4): 24-29.

Öztürk, Ç., Çay, T., Tetikkurt, S., Kasımogulları, E.V., \& Karacan, T. (2019). Case report of atypical endometrial stromal cells in an endometrial polyp and giant osteoclastic cells in leiomyoma in the same patient: Is it a coincidence or is it the result of treatment with tamoxifen? Acta Biomed. 2019 ; 90 (4): $572-76$.

Palumbo, R., Sottotetti, F., Quaquarini, E., Gambaro, A., Ferzi, A., Tagliaferri, B.. ..., \& Bernardo, A. (2019). Patterns of treatment and outcome with 500 mg of fulvestrant in postmenopausal women with positive metastatic breast cancer for hormone receptors / HER2 negative: a multicenter Italian experience in real life. Therapeutic advances in medical oncology 2019 jun; 11: 1758835919833864.

Pavilidis, N.A., Petris, C., Briassoulis, E., Klouvas, G., Psilas, C., Rempapis, J., \& Petroutsos G. (1992). Clear evident that long-term, low-dose tamoxifen treatment can induce ocular toxicity: a prospective study of 63 patients. Cancer. 1992 Jun 15; 69 (12): 2961-4

Pereira, A. S, Shitsuka, D. M., Parreira, F. J., \& Shitsuka R. Metodologia da Pesquisa Científica. 1º. Ed. Santa Maria/RS: UAB/NTE/UFSM. 2018. Disponível em: <Lic_Computacao_Metodologia-Pesquisa-Cientifica.pdf (ufsm.br)> Acesso em 03 Mar 21

Perrone F., Nuzzo, F., Rella, F.D., Gravina, A., Iodice, G., Labonia, V, ..., \& Matteis, A. (2015). Weekly docetaxel versus CMF as adjuvant chemotherapy for older women with early breast cancer: final results of the randomized phase III ELDA trial. Ann Oncol. 2015 Abr; 26 (4): 675-82.

Pompeo, D.A., \& Rossi, L.A. (2009). Revisão integrativa: etapa inicial do processo de validação de diagnóstico de enfermagem. Acta paul. enferm. 2009; 22 (4): 434-438.

Qadir, D., Chua, M., \& Sulaiman S. (2019). Retained products of conception in hysteroscopy in a patient with breast cancer on tamoxifen. BMJ Case Rep. 2019 Ago 30; 12 (8): e230635.

Robertson, J.F., Bondarenko, I.M., Trishkina, E., Dvorkin, M., Panasci, L., Manikhas, A., ..., \& Ellis, m.J. (2016). Fulvestrant 500 mg versus anastrozole 1 mg for hormone receptor-positive advanced breast cancer (FALCON): an international,randomised, double-blind, phase 3 trial. The Lancet. 2016 Dez 17; 388 (10063): 2997-3005.

Silva, I.M.C., \& Gonçalves, E.G.R. (2017). Câncer de mama e meio ambiente: uma revisão integrativa. São Luís, 2017.

Sedloev, T., Vlahova, A., Usheva, S., Vasileva-Slaveva, M., Spiridonova, T., \& Spirdonov, J. (2019). Long-term survival and complete response to anastrozole in breast cancer patients with only skin metastases. Anticancer Res. 2019 Ago; 39 (8): 4393-98.

Segala, D., Gobbo, S., Pesci, A., Martignoni, G., Santoro, A., Angelico, G., ..., \& Zannoni, G. F. (2019). Uterine tumor related to tamoxifen similar to ovarian sex cord tumor (UTROSCT): case report and literature review of this possible association. Pathol Res Pract. 2019 Mai; 215 (5): $1089-92$.

Smeltzer S.C., Bare, B.G., Brunner, \& Suddarth. (2006). Tratado de enfermagem médico-cirúrgica. Guanabara Koogan 2006 (Rio de Janeiro); 10 (3).

Sorscher S. (2019). Quantitative assays of mRNA expression and synchronous breast cancer: case report. Case Rep Oncol 2019; 12 (2): 418-20.

Tanaka, A., Yamashita, C., Hinogami, H., Shirai, H., Yamamura, J., \& Itoc, R. (2019). Localized adverse skin event induced by anastrozole as an adjunctive treatment for breast cancer: case report. Dermatology Case Reports 2019 jan/abr; 11 (1): 57-63.

Tenti, S., Giordano, N., Cutolo, M., Giannini, F., \& Fioravanti, A. (2019). Primary antiphospholipid syndrome during treatment with aromatase inhibitors: case report and literature review. Medication 2019 Mar; 98 (13): e15052.

Timmers, L., Boons, C.C.L.M., Kropff, F., Vem, P.M.V., Swart, E.L., Smit, E.F., ..., \& Hugtenburg, J.G. (2014). Adherence and patients' experiences with the use of oral anticancer agents. Acta Oncol. 2014 Fev; 53 (2): 259-67.

Visvanathan, K., Chlebowski, R.T., Hurley, P., Col, N.F., Ropka, M., Collyar, D., ..., \& Lippman, S.M. (2009). American Society of Clinical Oncology Clinical Practice Guideline Update on the Use of Pharmacologic Interventions Including Tamoxifen, Raloxifene, and Aromatase Inhibition for Breast Cancer Risk Reduction. J Clin Oncol. 2009 Jul 1; 27 (19): 3235-58.

Xie, Y., Li, Y., Zhang, Y., Zhang, S., Li, W., Guan, X., ..., \& Wang, B. (2019). Fulvestrant 500 mg versus Exemestane in postmenopausal women with metastatic breast cancer resistant to non-steroidal aromatase adjuvant inhibitors in clinical practice: a multicenter retrospective study. Clinical breast cancer 2019 jun; 19 (3): 452-58.

Woodford, R.G., Becker, G.J., \& Jain, A. (2019). Leukocytoclastic vasculitis associated with use of aromatase inhibitors. Intern Med J. 2019 set; 49 (9): 116267.

Whitmer, R.A., Quesenberry, C.P., Zhou, J., \& Yaffe, K. (2011). Timing of hormone therapy and dementia: the critical window theory revisited. Ann Neurol. 2011 Jan; 69 (1):163-9. 